\title{
The Tribal Philosophical Thoughts of the Higaunon of lligan City, Philippines
}

\author{
Prof. Artchil C. Daug, MIH \\ Mindanao State University-lligan Institute of Technology \\ Ms. Ashera Dyan T. Neri, AB \\ St. Michael's College
}

\section{Doi:10.5901/mjss.2013.v4n9p74}

\begin{abstract}
Studies on tribal philosophical thoughts are rare or non-existent in a Philippine society that included over a hundred tribes. This study brings into mainstream Philippine philosophy the thoughts of the Higaunon tribe regarding space and time, being and the self, ethics, and epistemology. Descriptive qualitative method was employed in this study. Higaunon stories from their culture and past were gathered through interviews with authoritative tribal leaders and shamans. Analysis was substantiated through community immersion and regular interaction with the tribal leaders so that structures of their thoughts can be revealed and considered as philosophical. The study found that the Higaunon consider space and nature as equally important as human beings, and duration instead of time prevails in their stories. Their "being" is found in the will of the Magbabaya, their one God. Their concept of "self" works under a tripartite structure that enables the learning of the past to be manifested in the projection of a future and in decision-making in the present. Decision-making is connected to their ethics, which essence is called Ginagawa, the source of love, compassion and judgment. The individual judges present circumstances and acts on them in the exercise of themselves as weighing scales referred as Gantangan. In terms of leadership, the Datu becomes Batasan Adansil, the exercise of Gantangan through tribal leadership. Epistemology is taken from human engagements and is kept within tradition by the Baylan. The study concludes that tribal philosophical thoughts are indeed viable and the Higaunon is a good example of it.
\end{abstract}

Keywords: tribal philosophy; Higaunon; Iligan City; indigenous peoples; Philippines;

\section{Introduction}

The current trend in tribal researches in the Philippine academe focused on the tribal communities only in the fields of history, sociology, anthropology and other related social sciences. The tribal researches of Alan (2001) on the Manobo tribe, Cruz (2001) and Ompang (2001) on the Mandaya, Cua (2001) on the Isama, Gloria (1987) and Guardados (2001) on the Bagobo, Lobos (2001) on the Kalagan, Onggo (2001) on the Matigsalug, and Rodil, et al. (1999) and Tangian (2011) on the Higaunon translated tribal experiences within the historical context of the nation, namely awareness regarding tribal rights to ancestral domains and ancestral lands, and understanding them through the lenses of poverty reduction, ethnography, demography, human rights, and ethnology.

In the west, there were already movements concerning awareness on tribal philosophical thoughts like the neopaganism of Mercia Eliade and the works of Vine Deloria Jr. on the philosophical foundations of native religions in the United States. Given the rich oral tradition of the indigenous peoples of the Philippines, it is ironic that such movements toward understanding tribal philosophical thoughts do not even exist. This study aims to be a pioneering work on the movement towards a greater understanding of the tribal communities through understanding their philosophy and worldview.

\section{Theoretical Framework}

Eliade (1954) argued that "Archaic man [man living under traditional indigenous cultures and ancient civilizations]...tends to set himself in opposition...to history, regarded as a succession of events that are irreversible, unforeseeable, possessed of autonomous value. He refuses to accept it and to grant it value as such, as history" (p. 95). Deloria, Jr. (1994) stated that the "western preoccupation with history and a chronological description of reality was not a dominant factor in any tribal conception of either time or history. Indian tribes had little use for recording past events" (p. 99). Both 
however believed that the traditional, archaic and tribal peoples possess a history of a different nature. However, the researchers simply argue that there is no need to consider the tribal past as something historical (as a "chronological description of reality") in order for it to have validity; and that understanding of tribal oral tradition as such is just an attempt to undermine and limit the possibilities of these oral narratives as means for disclosing what it really means to think like the tribals.

The central paradigm of this paper is a modified version of historicism, especially in understanding how philosophical thoughts emerge from tribal oral narratives. In his Elements of the Philosophy of Right, Hegel (1821) maintained that wisdom could only emerge after concrete historical events occur (pp.12-13). The researchers propose that in the absence of history, the tribals have stories and other narratives that are considered central to the understanding of their past experiences. The examination of these experiences is a way to establish the philosophical thoughts of the tribe.

\section{Methodology}

The general method of this study was that of compiling through interviews the Higaunon past from their available oral narratives. Interviews were also used for corroboration purposes whenever applicable. A focus group discussion was initiated with the intention of ascertaining the possible limitations of the paper (see the discussion on epistemology). The informants were not given a specific set of philosophical questions but were made to answer inquiries on their culture and past. Community immersion was used to merge horizons with the Higaunon informants. Informal interviews were conducted within the tribal lifestyle itself either through an early morning walk by the hillside, or in ordinary conversations after dinner. Interpretation became an apparent need for the Higaunon cannot answer direct philosophical questions. The second group discussion was initiated for the Higaunon to share the stories about their past. Through the interpretation of these stories, Higaunon philosophical thoughts are disclosed.

\subsection{Sampling and data collection method}

The Sangcoan clan in lligan City was selected as respondents for this paper because they belong to the Datu-Baylan (Tribal Leaders-Shaman) line, a royal line in Higaunon culture. As this is a descriptive study, the researchers used the purposive non-probability sampling procedure. The main respondents were Baylan (Shaman) Eladio Sangcoan, his wife Bae (Female Tribal Leader) Carmelita Sangcoan, and their son Mangohod ha Datu (Young Datu) Kilala Lanelio Sangcoan. All the stories in this paper came from the shaman and his wife, while further elaboration and translation was provided by their son. Apart from the Sangcoan family, Mangohod ha Datu Kaela Fausto Demeterio, a well-travelled Higaunon who mastered agriculture through the Ifugao tribe in the island of Luzon and cultivated domains in several parts of the Mindanao island. Some of the data were also contributed by Bae Kiram Connie Saturno, a Higaunon tribal leader from a neighboring community near lligan City.

\section{Finding and Discussion}

The researchers were able to gather at least ten stories and a few general description of the Higaunon culture. From these stories were extracted the Higaunon philosophical thoughts. Note though that knowledge, in the western tradition, is a product of scientific and objective studies. There is an objective reality from which man acquires data. However, knowledge and wisdom for the Higaunon came from the deities; thus, the necessary rituals. Tradition and longevityboth outcomes and gifts from the divinities rather than scientific evidences-define truth. It is best to understand Higaunon knowledge not as a section of a conglomerate universal knowledge that most educated people understand today.

\subsection{The Stories}

The first oral account was entitled Nanangun ho Alagasiya about a time when giants still roam Mindanao. It tells the story of a tribal leader and a shaman who used their wits instead of their power to defeat a brutal giant bent on destroying a Higaunon settlement. The second one was Ambawa; about a rat who was blinded by his delusion to sing the most beautiful song that he failed to observe his surroundings, which resulted to his failure to learn the said song and eventually to his death. There was also a narrative titled Kaboli-Boli, a man who was obsessed with this self-worth that 
he projected his value towards his own feces. Another narrative was Su Pino ha Datu daw Su Pito ha Pipinditon, which was about the challenges met by seven Higaunon warriors as they were tested by a rival tribal leader. The triumph of the warriors became possible only with the help of their old and wise father, who was their tribal leader. The next story was Kalimanggud, which was about a caterpillar, challenged by a snake in terms of beauty. The caterpillar won when he became a butterfly. The sixth was a narrative on the Higaunon ancestor named Baybayan, whose lineage came from the shamans that fought the Spaniards during the Spanish conquest of Mindanao. Next was the story about Apo-a Pamulaw, a kind-hearted tribal leader who welcomed both the Muslims and the Spaniards in his domains. Then there was the story of Bata Buling, a despised man known as "dirty" since childhood but became surprisingly strong and eventually turned out to be a very capable leader. Mantaw-antaw was a story of a man who was warned by Magbabaya (god) of a great flood coming from a river near their domain. The last narrative was Su Tultulanon ho Tambacan, a story of how the Higaunon ancestor Lungkayaw defeated and massacred a group of Iranun pirates about to raid their land. Shaman Sangcoan also included the Higaunon story of the creation of the world and of man, but this will be discussed in a later section.

The most obvious observations that one can get out of these stories are that they are not definite in time and space, and that chronology does not matter at all. In the telling of these stories, there was no attempt to arrange them in a chronological manner the same way history arranges dates and events in a chronological timeline. However, what is important here is that truth is not a subject of verification but that of tradition. When the researchers asked whether these stories did happen, the shaman Eladio Sangcoan answered that they did. Since these stories existed for generations, they are beyond questioning.

\subsection{Space and Time}

Placing the stories in a synchronic manner manifests outright the absence of the modern and contemporary conception of time, and the prevalence of human experience within space rather than the space itself. Contemporary society is much accustomed to tracing space in relation to time that the researchers felt great discomfort when these stories ended up not having definite time and specific locations. The Higaunon place emphasis on the experiences that occurred in space and see duration in it rather than subjecting it to time. Phrases like "in the neighboring land" and "on the top of the mountain" (in the Alagasiya), "faraway places" (in Ambawa), "two kingdoms facing each other" (in Su Pino ha Datu daw Su Pito ha Pipinditon), "the wide plain" (in Kalimanggud), "the world specifically to the mountains" (in the Baybayan), "Spaniards from the north" (in the story of Apo a Pamulaw), "In the midst of a thick forest in a mountain" (in Bata Buling), and "on this world" (in the story Mantaw-antaw) offer the observer with a glimpse of the Higaunon's understanding of space.

The Higaunon accepts the benevolence of the natural world. There was no need to ask metaphysical inquiries on the nature of space, for it is merely accepted as such, as nature. Space is a given-part of creation-what is relevant are the things done on and in it. It is enough to point to a general understanding of the "where", without giving weight to the "where exactly" because the relevance is on the meaning of the events. Specific locations are not relevant to the telling of stories. Chronological reality is fundamentally absent when recalling past events considered relevant by the Higaunon. When Kaboli Boli saw a fly on his feces, it is not on this disturbance in space that made him angry. The elements of space, particularly his feces, are only given meaning by his fondness for his life; for space is, according to Kaboli Boli, "connected to my entrails, the very entrails that I woke up with in this world". It was not dirty inasmuch as it was part of him. In this story, like many others, space is a mere background. Because space, within which nature settles almost in static, is created by the deities, it is alienated from active participation in most of the stories.

The same thing can be said when the tribal leader Bataay set a trap against Alagasi the giant. The agong (gong) that the giant was so fond of found a twin in space in the shape of a beehive, which coincidentally appear provided by nature for the triumph of the hero. When Ambawa went on his quest for a song, one is not offered a sense of direction at all. It was only when the Pugo (an owl) specified a place that space arrived unfortunately to the ruin of Ambawa. He was instructed not to go to certain place, yet he did. It was the cause of his death.

The modern and contemporary understanding of time found no position in any of the stories. The sense of duration, not the sense of time, mimics the Higaunon understanding of duration in space. This is not surprising since the Higaunon did not develop a calendar as extensive as that present in some sophisticated ancient societies. Duration in a day is determined using the position of the sun and "the direction of shadows". They do not tell time nor have any understanding of it the same way as most people today would (K. F. Demeterio, personal communication, January 14, 2013). Longer durations are measured through the phases of the moon (E. Sangcoan, personal communication, October $26,2012)$. The sun and the moon played its role in knowing that a certain duration in space has occurred. 
The glaring consequence of these views on space and time are as follows. Since space is alienated from human activity (space considered as an entity in the background, not as human possession or subject to human control), treated as sacred and as belonging to the proper domains of the deities rather than that of humans, private ownership of land became impossible. "Ang Lumppad" (nature) is a creation of the deities and so are human beings; thus, it is difficult for the Higaunon to imagine that a creation can own its fellow. Many of the Datu during their meeting, where the researchers were invited as guests, emphasized that they do not worship nature. Instead, what is mistaken by modern man as nature worship is the Higaunon's proper gesture of respect to the natural world that stand co-equal in dignity with human beings. "Sama rana sa murespeto ka sa tag-iya sa balay nga imu bisitahon o kanang murespeto ka sa mga butang nga dili imoha" (That is the same when you respect the owner of the house you are visiting or when you respect properties that are not yours) (K. L. Sangcoan, personal communication, January 12, 2013).

\subsection{Being and the Self}

There are two realms in the interpretation of reality by the Higaunon. The concept of space and time presented above composes what the Higaunon believe to be the material realm, which is signified simply as Lumppad (nature). The spiritual realm, signified as Baya, is the realm beyond space and time. Before the Lumppad came to be, the Magbabaya resided within the Baya. The Magbabaya is so powerful that it exists in- and for- itself. "Nagpuyo siya didto sa iyang kaugalingong kagahum" (The Magbabaya resided in its power) (K. F. Demeterio, personal communication, January 14, 2013). Then within this power, the Magbabaya created from within itself: Magbabaya Nangadun, Magbabaya Luminimbag, and Magbabaya Nananghaga. The Magbabaya Luminimbag then created the Lumppad through the Hulmahan Agpangan, words in dreams used in the "paghulma sa kalibutan" (moulding of the world) and in the "pagbuhat sa tao" (creation of humans). This happened within the spiritual realm called Limbagan (the place where everything is created).

After nature took shape upon creation, the Magbabaya Luminimbag then created the first humans, known as Natanyag and Natanghaga. They were neither male nor female. The Magbabaya Nangadun was responsible for providing faces and appearance to all creatures. The Magbabaya Nananghaga was responsible for giving names to all of creation. In these early moments of human existence, the Baya and the Lumppad were not far apart that if someone exists in the Lumppad he or she could reach and feel the Baya with his or her arms. (E. Sangcoan, personal communication, October 26, 2012). Thus, there existed the spiritual realm of the Baya and the material realm of the Lumppad.

This was where "being" began. The will of the absolute and eternal Magbabaya held sway among all creations, all of Lumppad. The Magbabaya provides meaning for everything, including the meaning of existence. "To be" is defined by the Magbabaya. As for the early humans, Natanyag and Natanghaga, they were offered the fruits of the Kalintubo, the Tree of Life in the Baya. They were to eat from the fallen fruits of the Kalintubo. From such fallen fruits the immortality of the two were secured, including eternal bliss. They were prevented from doing only one thing, to get the fruit from the tree itself and to eat it. Nevertheless, the Magbabaya wanted to test the capacities of the two by sending entities to tempt them in getting the fruit from the Tree of Life. Unfortunately, they disobeyed the Magbabaya and committed the first "sala" (fault or inappropriate behavior). There and then "nagsugod ang kinatao sa bae og laki" (started their lives as woman and man) (E. Sangcoan, personal communication, October 26, 2012).

They were no longer provided the fruits from the Tree of Life and they became mortals and suffered the finite nature of existence just as the rest of Lumppad. All their descendants shall then become mortals too. The Baya began moving away from the Lumppad until its gap can no longer be fathomed. Thus, began man's becoming-given the freedom to choose a life of his own with purpose unknown and with immortality gone. The "self" is comprised by the being provided for by Magbabaya and human actions. This story of the beginning of everything demonstrates well the structure of the mind of the Higaunon Baylan. Being and self are defined in two realms. "Being" as the nature of existence provided for by the Magbabaya, and the "self" as the nature of existence within the world or man's worldhood, the self that can determine the "l".

"Being" is the role already acquired by birth. The lines of Datu and Baylan are already determined by the Magbabaya, so one can be born following the footsteps of those who became Datu or Baylan in the clan or one is simply born to a common family. A Higaunon, in a sense, is thrown into the world by the Magbabaya and he or she has no dictates over which family he or she is born with. The Higaunon is molded by the Magbabaya to existence, but "destiny" is limited to the circumstances the Higaunon find himself or herself in. Mantaw-antaw cannot go against circumstances provided by the Magbabaya. The fact of the Higaunon's existence is no longer necessary to inquire, the same way, as 
there is no need to ask the essence of space or nature. Inquiries on the nature of things, such as those in metaphysics, cannot change the "fact" of one's existence. This is the Higaunon's being.

The "Self" or Kagwolong is the understanding of the Higaunon individual of his or her role in Higaunon society (being) and awareness of his or her actions that resulted into choices of what he or she can become (becoming). The Higaunon sees himself as a creature of the Magbabaya, acknowledges his being upon recognition of the clan circumstances he found himself in, and then determines his becoming by creating the path of his career. It is through this engagement in the world that Kagwolong is weighed. Though in the spiritual realm one may assume that the Magbabaya values its creation, in the material realm the action and engagement of the Higaunon individual determines the worth and value of the individual. In a personal conversation with Baylan Dionesio Sangcoan, he complained about a distant relative of his who ruined his path by going against his parents and the clan, dropped out of school, and became a drug addict. "Kanang in-ana nga tao, nahulog nga walay bili. Mas maayo pa magbuhi og iro, sa saktong pagka storya" (A man like that is worthless. It is better to raise a dog, practically speaking). So when the researchers asked if the value of the individual is already set, or that one must prove value through actions, he agreed on the latter. (D. Sangcoan, personal communication, October 27, 2012).

The becoming of the self can be viewed in a tripartite structure. First, the Kagwolong, the identification of the Higaunon of his or her "self" and everything that happened to the self as it stands in the present. The Kagwolong includes all human engagements that the Higaunon undertook and the role (being a tribal leader, a shaman, a farmer, etc.) the Magbabaya set for him. The Magbabaya determines a Higaunon's being. Then second, the Higaunon, by looking at his engagement in the world and by understanding the role the Magbabaya set for him, utilizes his Kagwolong to project a future for himself or herself. In any given moment, the Higaunon looks at his past and his role and weighs it to project future outcomes of his choices. Long before Islam and Christianity influenced the Higaunon, the bases of their lives were actual engagements in the world and not scriptures and texts. The Higaunon used their lives and its connection with nature (its involvement in the world) as the source of its decisions and choices. They never needed any book whatsoever.

However, just as the Magbabaya tested Natanyag and Natanhaga, so are the Higaunon tested with its ability to weigh situations every day. "Mao nang dili mawala sa ato ang pagsulay" (that is why we always face trials in life) (E. Sangcoan, personal communication, October 26, 2012). Thus, the third is that the present continues to provide trials for the self in order for it to make choices. A consequence of the first sala (fault), the Higaunon must face trials and act on different situations. The self must act under a sense of propriety. Its Kagwolong is already provided by its being and by its past, it has the ability to project future outcomes, but it must learn to weigh the present. This act of weighing is what comprises Higaunon ethics.

\subsection{Ethics}

At the heart of Higaunon ethics is the concept of balance. In the stories, this is a repeating theme. The great devourer giants Alagasi and his family were made to pay for their crimes by the Datu Bataan using their weakness as the source of their downfall. Their lack of wisdom made them devour their servants, and that lack of wisdom resulted to an unbalance. The same lack of wisdom was used for their death. Ambawa was made to realize that gaining something means losing something. He gained a song, but lost something in return. When he succumbed to his whims by doing what was forbidden, he lost the song and eventually his life. Kaboli Boli by defecating caused an unbalance in his surroundings. A fly came for his feces but it also invited the curiosity of a chicken, which got the attention of a dog, which in turn got the attention of a boar. Since Kaboli Boli gained satisfaction in his action, he must realize that if he value his feces extraordinarily then he must guard it. His anguish ended only upon this realization. The seven warriors on the other hand were made to realize by the Pino ha Datu that the arrogance and strength of youth must be complemented by the wisdom and knowledge of old age. They are strong that is true, but since they lack wisdom, they endangered themselves and was only saved through their loving brother who learned from their wise father, who in the beginning of the story they agreed on burying alive as he was old and already a nuisance. Agyu, Baybayan and the Spanish Missionary who courted Agyu's sister, despite having been granted a place in Baya, still requested to return to Lumppad. It was granted but the three returned as Dwata (nature spirits) in exchange.

This give-and-take structure, which echoes the fate of Natanyag and Natanghaga, and the occurrences of unbalance because of the whims of humanity, is a good demonstration of the concept of Ginagawa (balance). There is balance in nature that is required to be kept, and this balance resemble the perfection, the oneness, of the creation of the Magbabaya. The Apo-a Pamulaw, for example demanded respect from the Spaniards for they are all created by a 
common God. Ginagawa is intrinsic in creation and as such is part of the Kagwolong of the Higaunon existence. To deny the Ginagawa is to deny oneself as being Higaunon thereby causing unbalance.

In ethical judgment, the Ginagawa becomes the concept of Gantangan (weighing or scaling), wherein the Higaunon weighs the circumstances of his life-or, in the case of the Datu during times of settling conflicts, weighs arguments and decides upon them. This system of weighing and keeping balance is called Batasan Adansil. The Batasan Adansil adjusts in every situation, uses the past as a guide for judgment and exercises the Gantangan to weigh things down and deliver justice. Judgments passed are recorded in memory and oral tradition and becomes part of the Kagwolong of the Datu in times when the Datu becomes Batasan Adansil, meaning the system of justice. Thus, the Batasan Adansil is thus a role played by the Datu in exercising judgment. In this instance, the Datu also becomes Gantangan in a political sense, for his decision becomes part of conventions that found expressions in oral tradition. In most cases, decisions are always towards keeping Ginagawa. There are hundreds of examples in this, but the Higaunon Datu and Baylan treats them as a compendium of laws already beyond the scope of this paper.

Human engagement is thus the dynamic process of becoming in the mandates of his or her being. The very nature of the Higaunon self is directly connected to the foundations of his or her ethics. In the decision-making process, the Datu observes as a Gantangan, as Batasan Adansil, in the moment, and projects possibilities of decisions and its outcomes from Kagwolong.

\subsection{Epistemology}

Knowledge in the Higaunon scheme of things is based on a hierarchy. Those who are seeking Higaunon knowledge faces the wisdom of the Higaunon shaman, and then undergoes rituals asking permission to the deities for knowledge to be imparted. These rituals play as doorways to Higaunon knowledge. The rituals are of two kind in this instance. The first ritual is for the basic understanding of Higaunon culture that is enough for some to become Mangohod ha Datu (a young tribal leader in the process of becoming wiser). In this level, the Datu learns the fundamental nature of ethics and knowledge contained in their Batasan Adansil. Experience grants him the rank of Pino ha Datu. The second ritual opens the door to spiritual knowledge so that the Pino ha Datu can study Linggas ha Tanod (spiritual wisdom) and may become a Poon ha Datu (literally "The Wisest One", generally called Baylan or the shaman). The Higaunon shaman is an authority on both the material and spiritual aspects of Higaunon existence. When the researchers asked Baylan Eladio Sangcoan if there are things that he know about the nature of the creation of the world other than what is in this paper, he remarked that he is limited to what the ritual allowed him to teach. In asking Mangohod ha Datu Kaela Fausto Demeterio about the meaning of the rituals, he apologized that he never had the knowledge on linggas ha ugsak, saying "aw, wala man kaayo ko ana" (I do not have much idea on that) (K. F. Demeterio, personal communication, January 13, 2013). The Bae, roughly considered as the female counterpart of the Mangohod ha Datu, cannot become a baylan because they cannot perform specific rituals, like sacrificing chickens, for "ang kahimtang sa babae kay gapanganak siya (she delivers babies)" and "kada bulan muagi sa Lumppad ang babae (every month she undergoes menstruation" (E. Sangcoan, personal communication, October 27, 2012).

This prohibitive nature of Higaunon knowledge manifests in their language itself. There is the Higaunon language for common usage that many of Higaunon still know, but the language of the shaman is the sangunsangun, the spiritual language that is now very rare in usage in Higaunon communities. The sangunsangun is the language of the finest ones and they use it without toleration for changes in structure. According to Mangohod ha Datu Kilala Lanelio Sangcoan, when words do not fit in the prescribed structure of usage in the sangunsangun, the shaman can interpret this as a form of treachery and mischief (K. L. Sangcoan, personal communication, January 12, 2013).

In general, the exclusivity innate in Higaunon knowledge created a defining limit in this study. There is a strict line that divides what the first ritual can offer for those who are merely researching, and for those who are on the process of being Mangohod ha Datu. The reader must remind himself or herself that not anyone can become a tribal leader or a shaman; that one must belong to the original line of Higaunon leaders that found its origin in the beginning of everything.

The extent in which Kagwolong affects engagement in the present, of how understanding of the past and knowing the fact of one's life, contributes to the projection of a future demonstrates the power of knowledge in Higaunon society. To reiterate a point implied earlier in this study, Higaunon knowledge is not statically objective and does not exist outside the tripartite structure of Higaunon Kagwolong to form an independent objective standpoint as a separate body of knowledge. Knowledge is an active participant to the understanding and identification of the Higaunon "being". Engagement in the world is the primary source of knowledge and knowledge is composed of lessons learned in the worldhood of becoming. Thus, wisdom-usually viewed in the modern world as a product of subjectivity-and 
knowledge - usually treated as a product of objective science-are not at all dissimilar. The story of the seven warriors facing the test of the Pino ha Datu is a good example. Saved in the end by the wisdom of the Poon ha Datu, the warriors were grateful and apologized for their recklessness in decision-making. However, the tests provided by the Pino ha Datu are tests of practical knowledge (not Sphinxian/philosophical riddles) that presupposes tremendous engagement in the world and not abstract understanding of reality.

Wisdom and knowledge are the same. They are dynamically modified through engagement and change within the world. The tripartite structure acting as the dynamo of Higaunon Kagwolong. Becoming is the process of change and change is intrinsic in the world. Bata Buling was an outcast because of his appearance and smell ever since he was born, but change turned him into someone unlike his name. The snakes were not wise in challenging the caterpillars to a beauty contest for they failed to acknowledge that change can transform the caterpillars to colorful and beautiful butterflies. Change made the Higaunon accept the impermanence of the world, and the impermanence of man. Knowledge cannot necessarily be universal and absolute (unchanging, characteristics of objective knowledge) for everything change and decisions must adapt to it.

In closing, it is indeed obvious how the elements of Higaunon thoughts explained in the preceding pages are connected to each other. Space and time, being and the self, and ethics are all intertwined into a body of knowledge. This body of knowledge is not a passive ivory tower overlooking everything from its objective standpoint, but an ubiquitous sun that permeates in the becoming of the Higaunon in the material world with the Baylan as its walking reminder.

\section{Conclusion}

This study shows that though the tribal peoples, like the Higaunon, does not possess a systematized philosophy, it is only a matter of training before it can be done. Their culture is rich in human engagements and experiences that what is only required is a creative mind to fully capture their thoughts and place them in a philosophical structure. This study, as mentioned before, is far from complete. Though hermeneutics was exercised to better understand Higaunon culture, the researchers can only imagine what a Higaunon philosopher, who is trained in the craft and remained loyal to his or her culture, can do. Nonetheless, looking at the findings of this study, there are many things that contemporary society can learn from Higaunon thought.

Knowing that nature is as much a respectable entity as human beings is paramount for any environmentalist. The Higaunon does not see themselves as mere caretakers of the world. They see themselves as living in and beside it. The respect made them treat nature just like human beings. Contemporary society poses itself as an overlord over nature that many members of it feel that it is either we save or destroy it. The Higaunon does not subordinate nature to the whims of man, but understands it as its equal. Many may criticize these people as animists and nature worshipers, but this is only because contemporary society mistakes the tribal show of respect for nature as a kind of worship. The Higaunon only worship the Magbabaya and the rest are merely expressions of Ginagawa.

Though to the trained eye Higaunon ethics appears akin to existentialist thoughts, their ethical standards are based on balancing personal whims and personal discipline. Kaboli Boli, Ambawa and the Seven Warriors reminds contemporary society of restraining the pleasure-seeking principle that dominates it. In the ancient days before the arrival of the Muslims and the Spaniards, the Higaunon came to live life without the usual instructional scriptures that determine human values, virtues, judgments, and behavior.

That knowledge is not just an objective exposition of reality (as a product of science), but a living and breathing wisdom is something the academicians of today may appreciate. Knowledge is not a passive entity looked upon as a model, but an active participant in the Higaunon's journey in life. Truth is that which works, the west needed the development of pragmatism to realize what was already exercised in Higaunon society many years before the JudeoChristian-Islamic traditions reached them.

\section{References}

Alan, M. (2001). The Manuvu of Baguio District, Davao City. In Mindanao Ethnic Communities Patterns of Growth and Change (pp. 2144). Philippines: University of the Philippines-CIDS.

Cruz, A. (2001). The Mandaya of Montevista, Davao del Norte. In Mindanao Ethnic Communities Patterns of Growth and Change (pp. 175-216). Philippines: University of the Philippines-CIDS.

Cua, L. (2001). The Isama of Samal Island, Davao. In Mindanao Ethnic Communities Patterns of Growth and Change (pp. 59-108). 
Philippines: University of the Philippines-CIDS.

Deloria, V. Jr. (1994). God is Red A Native View of Religion. Golden, Colorado, United States: Fulcrum Publishing.

Eliade, M. (1954). Cosmos and History: The Myth of the Eternal Return. United States: Harper and Brothers.

Gloria, H. K. (1987). The Bagobos: Their Ethnohistory and Acculturation. Quezon City, Philippines: New Day Publishers.

Guardados, J. J. R. (2001). The Bagobo Clata of Calinan, Davao City. In Mindanao Ethnic Communities Patterns of Growth and Change (pp. 1-20). Philippines: University of the Philippines-CIDS.

Hegel, G. W. F. (1821). Elements of the Philosophy of Right. Translated by H. B. Nisbet and Edited by A. Wood. United States: Cambridge University Press.

Lobos, D. (2001). The Kalagan of Madaum, Tagum City. In Mindanao Ethnic Communities Patterns of Growth and Change (pp. 109174). Philippines: University of the Philippines-CIDS.

Ompang, M. (2001). The Mandaya of Davao Oriental. In Mindanao Ethnic Communities Patterns of Growth and Change (pp. 217-257). Philippines: University of the Philippines-CIDS.

Onggo, M. (2001). The Matigsalog of Marilog District, Davao City. In Mindanao Ethnic Communities Patterns of Growth and Change (pp. 45-58). Philippines: University of the Philippines-CIDS.

Rodil, R. B. et al. (1999). The Ancestral Domain Claim of the Impahanong-Amusig Tribal Council Organization. The Mindanao Forum, 14(1), 99-134.

Tangian, M. C. B. (2011). The Higaonon Ethnohistory of Rogongon, Lanao del Norte. United States: Xlibris Corporation. 